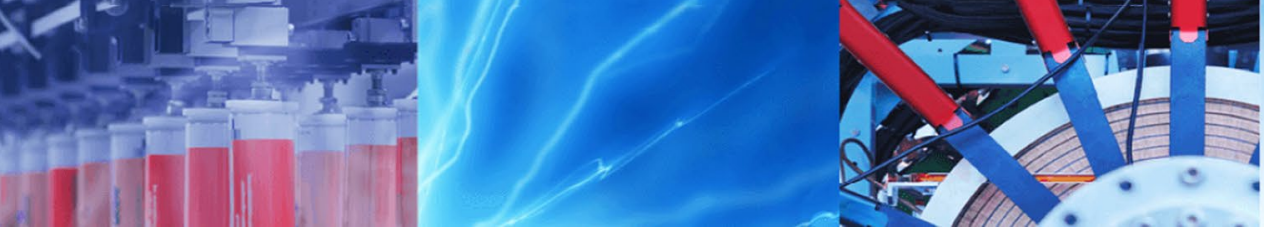

Research Article

\title{
Computation of Rayleigh damping coefficient of a rectangular submerged floating tunnel (SFT)
}

\author{
Md. Hafizur Rahman ${ }^{1,2}$ (D) Chhavi Gupta ${ }^{1}$
}

Received: 28 December 2019 / Accepted: 30 March 2020 / Published online: 20 April 2020

(C) The Author(s) $2020 \quad$ OPEN

\begin{abstract}
The dynamic behaviors of the submerged floating tunnel, a buoyant structure of high slenderness, are a matter of concern since it is surrounded by the huge hazardous effects called hydrodynamic, seismic and functional action. Modal analysis and Rayleigh damping coefficients play a significant role in dynamic analysis, but it is not sufficiently simple to predict the reasonable damping coefficients named $a$ and $\beta$. The present paper outlines the modal analysis and the calculation of Rayleigh damping coefficients that provide the natural frequencies, mode shapes, mode's motion as well as coefficients $\alpha$ and $\beta$. To compute the Rayleigh damping coefficients, $2-10 \%$ damping to the critical damping has been assumed for this analytical study. For the analysis, an FEA-based software ANSYS is utilized successfully. It has been seen that the fundamental frequency and Rayleigh damping coefficients ( $\alpha=0.946$ and $\beta=0.00022$ ) of the SFT are reasonably high and it is under noticeable damping.
\end{abstract}

Keywords Buoyant · Slenderness · Rayleigh damping coefficients · Mode's motion

\section{Introduction}

With the racing era of modern science and technology, structural engineering is going ahead to rescue the new challenges. The waterway crossing is one of them, and usually, a bridge is used, but a submerged floating tunnel (SFT) can be used for coming out of this challenge [1-5]. Though immersed tunnel, undersea tunnel, and bridge of long span have been being used for decades ago, now the curious concentrations are focused on the submerged floating tunnel as it is the new one and it gets the popularity day by day due to its interests [2]. Among the possibilities of waterway crossings, the SFT is chosen when the length and depth of the waterway are excessively high. The SFT can easily solve the concerning environmental problems; lesser project costs and can be introduced for its anti-vibrational behaviors [1-4, 6]. Being a slender structure, the perspective proportion of SFT, which is characterized as the proportion of span to the characteristic length of tube cross section, is as a rule as huge as $10^{2}-10^{3}$. It implies that the energetic behavior of SFT would like a slim bar limited by ties. Hence, the interaction between SFT and encompassing liquid is noteworthy. Here, due to the slenderness of SFT, the deformation of SFT beneath hydrodynamic loads composes distinctive vibration modes. In this way, it is not fitting to accept that SFT is inflexible when we compute the liquid strengths applying to it. SFT tube is by and large inundated within the profundity of 20-30 m beneath the water, once collision mishaps or fear-based oppressor assaults happen amid its operation; the result is more genuine [7]. Even though SFT is put beneath the water surface at a certain profundity, the surface wave has an imperative impact on its energetic reaction due to the slenderness of structure. Additionally, the wave strengths and energetic reactions of SFT are coupled, which must be taken into consideration

Md. Hafizur Rahman, hafizurcivil91@gmail.com; Chhavi Gupta, er_chhavi89@yahoo.co.in | 'Sharda University, Greater Noida, India. ${ }^{2}$ Faculty of Engineering, University of Debrecen, Debrecen, Hungary. 
within the numerical recreation. Due to having a few stunning facilities, it was first patented in Norway in the nineteenth century, but it got the advanced achievements in recent few years due to the complexity of analysis. Several proposals have been made, but SFT has never been built (as of 2016) [2].

A rectangular cross section is the easiest way to construct the tunnel. Nowadays, it is mostly used in the immersed tunnels where hydrodynamic pressure is less. To improve the hydrodynamic resistance, keels can be used (steel/concrete) and this idea was used in the "Tsing Ma Bridge" (truss brackets) in Hong Kong [8]. The rectangular section is also now considering the submerged structures in a different situation because of its feasible carriageway because the elliptical or circular section needs more area compared to the rectangular one with having some specific feasibilities [9]. Another cross-sectional configuration of the tunnel is one or more circular tubes holding the traffic lanes linked by frames and finally hidden by a shell. Different studies show that the circular section provides the best results in the case of submerged structures. The circular cross section is selected for the feasible studies and primary design due to its structural (rational) response to the hydrostatic pressure since only compressive stresses are induced and no bending in the cross-sectional plane and no longitudinal cracks are produced by the hydrostatic pressure. Moreover, it also features a good response to hydro-elastic stability due to its polar symmetry and it is also free from the torsional divergence [4]. Li and Jang [8] performed an analytical study as a breakthrough point on section form (rectangular and elliptical) and reported for displacement, structural stress, and hydraulic prosperities. They found the elliptical section is better for the restriction of structural deformation against the induced pressure, displacement, principal tensile stress, maximum tensile stress, and maximum principal pressure as compared to the elliptical section. So, the bearing capacity of the rectangular section is relatively less as compared to the elliptical section. On the contrary, the complicated procedure is required for it as compared to the rectangular cross section. Elliptical, polygon or elongated shapes are also considered too, especially, where a large speed of water is expected horizontally because of their higher horizontal strength and stiffness. Having several disadvantages, in this present study, the rectangular section is chosen to supervise the mechanical behaviors under a certain range of damping ratio. Coutu et al. (2012) showed the damping as the most driver of vibration sufficiency when excitation happens near to the common recurrence of a structure in streaming water. Though there is a risk of galloping which happens in current at higher velocities (usually at reduced velocity, $U r \geq 1$ ) in the rectangular cross section than the circular cylinders; hence, it does not affect much if the SFT is set at the low-velocity region [2].

As discussed above, there are numerous different sources of gradually changing natural powers of low size. As such, they would regularly not do any hurt to the SFT and its components in case it had not been for the threat of resonance with major vibration modes of the burrowing tube. One secure way of managing with this challenge is to plan the tube and its bolsters such that the lower principal eigenperiods are securely underneath the periods of these powers. Within the more recent studies in Norway, the primary eigenperiod has hence been kept underneath $5-6 s$ to restrain the energetic impacts of the bigger, to begin with, arrange wave powers [10]. This, in any case, may have a huge fetched punishment since it, for the most part, would require a moderately huge number of anchoring points and tethers.

\section{Structural damping for SFT}

According to Chakrabarti (2004), two basic approaches must be considered for floating structure, frequency domain, and time domain. The frequency-domain uses to solve a simple problem, in general, attain by a differential equation. But this method only works for linear equations; all nonlinear equations must be converting to linear. That is the limitation of this method. As for the time domain, use numerical integral for equation from all nonlinear systems. Examples from this equation are drag force, mooring force and damping viscosity. In API RP 2T. 1987, structural dynamic analyses for an offshore structure are frequency-domain analysis and time-domain analysis. Frequency domain analysis simulation of the events is carried out in each time by frequency interval. Modal analysis of a structure plays an utmost of importance to the stability and design of structures. As a result, it deserves intensive characteristics and modifications while conducting the operations because of the fundamental frequency. It is crucial to know the different modes of the structure; the mechanical behavior of that structure is known which is the so-called mode shape which shows the direction of the mode's motion (horizontal, vertical, and torsional) $[5$, $6,11-14]$. From various characteristics of modal analysis, modal mass and damping ratio are the most major considerations for the successful results. And the impact is major right on reverberation or resonance; an enhancement calculation of 10 is gotten with a $5 \%$ damping, whereas it gets to be as it were 2.5 with a $20 \%$ damping calculation. Such variety can be the distinction between a solid structure and a quickly falling flat one, and the paper presented a clear proof of damping values expanding altogether with water velocity [15]. As a consequence, the damping effects 
of hydrodynamic action are directly proportional to the velocity of the water and these damping effects are eagerly dependent on drag coefficients of water confirming the different Reynold's numbers for the different flow. In the case of vortex-induced vibration (VIV), the impact on the hydrodynamic damping in the Lock-in area is usually put to zero because of including the damping in the model [16]. Usually, a 5\% damping ratio is used for the concrete structures $[11,12,14,17-19]$. But few researchers suggest a $2 \%$ to $10 \%$ damping ratio in case of large structures depending on the safety issues [11]. On the other hand, a very little amount of damping ratio is considered in the case of marine, offshore structures, and especially submerged structures. For steel and concrete offshore structures, the damping ratio varies from 0.2 to $0.5 \%$ and 0.5 to $1.5 \%$ of the critical [20]. Depending upon the shell modes and beam modes, damping ratios are $1-2 \%$ and $2-5 \%$, but it is recommended to use total damping of $2-5 \%$ [21]. For instance, the damping ratio of the submerged pipeline may increase from $2.4 \%$ to $5.5 \%$ in seawater [22]. Consequently, a 2-10\% damping ratio is chosen for the SFT analysis considering the offshore and large systems to determine the damping coefficients, as the hydrodynamic damping is formed from the radius damping and added damping. During the modal analysis, the participated modal mass in a direction must be greater than $85 \%$, while some experts said it must be at least $95 \%$ and 2.5 times of $m$ th modes are required for significant modes for Rayleigh damping $[12,14,17]$. And then m modes should accommodate approximately $95 \%$ of modal mass significant, so a total of 375 eigenmodes are required for estimating the $a$ and $\beta$. Damping behaviors of a structure depend on the value of $a$, likewise very little damping, little damping, noticeable damping, and pronounced damping [16].

\section{Structural modeling}

The transverse plan must fulfill three crucial viewpoints: the structural issue, the weight adjusts, and the inner space. The slimness and the estimate of an SFT are like a bridge, and the submergence of it is like a dispatch or submarine, whereas the slimness, the estimate, and the submergence of SFT are comparable to nothing. The SFT must be set in such a way so that any water vehicles can pass easily over the SFT, and the depth of the free passing vehicles should be considered on the regional naval data. In accordance with the NOAA navigation chart (No. 12335), although $20-50 \mathrm{~m}(65-164 \mathrm{ft})$ water clearance is quite enough for the free passage of the water vehicles, it may vary up to $236 \mathrm{ft}(72 \mathrm{~m}$ ) confirming the regional navigation of water vehicles. In the case of lakes and shallow rivers, about $20-25 \mathrm{~m}(65-82 \mathrm{ft})$ is mostly chosen. Besides, no genuine SFT exists. In this way, no scientific show has ever been approved. In this manner, the physical show is fundamental. The extreme purpose of building a demonstration is not to get figures but to get the apparatuses that can get the figures and to see through the figures, past them. The insides space prerequisite depends on the activity clearance (i.e. the least space prerequisite for activity characterized by the significant code), the space for inside establishments such as ventilator and flame resistant boards, and the additional space for pleasing development resilience from the construction and inundation of burrow component. The shape of SFT is an identical criterion depending upon the environmental hazard. Although the circular and elliptical shapes have much feasibility as compared to a rectangular tube because of the action of the hydrodynamic pressure, the rectangular tube has some advantage in constructional as work. Therefore, in this present study, a rectangular SFT, a simple tubular segment having the horizontal axis of symmetry, is considered. It is anchored to the seabed with steel cables to fix it in its position shown in Fig. 1. The tunnel tube is made by concrete which has the modulus of elasticity of $4.8 \times 10^{6} \mathrm{psi}\left(3.30948 \times 10^{8} \mathrm{~N} / \mathrm{mm}^{2}\right)$ and Poisson's ratio of 0.2 . The SFT has been planned to carry the vehicles only. In the SFT, vehicles can move in one direction. The carriageway used for the vehicles in the SFT is confirmed by the AASHTO. The major details of the SFT are given in Table 1. The avoidance not as it were deciding the part drive of the structure but moreover influences our security feeling if we pass through an SFT. The increasing speed will make us have "seasickness," in case the esteem of it is expansive due to the disgraceful plan of the structure. The SFT will experience the vibration owing to the vehicle's movement. If the vibration frequency exerted by the vehicle is close to the natural frequency, then the resonance can happen which may cause the failure of the SFT tube. In structural design, we got to dodge resonance by letting this ratio distant absent from the esteem of 1 , ready to either alter the mass of the tube or the solidness of the lines or present more damping into the framework. In addition to the vehicle vibration, the SFT will also get the additional frequency due to hydrodynamic actions and earthquake. Though the effects of the earthquake are reasonably less as compared to the hydrodynamic effects because it is anchored by cable. In this paper, modal analysis is carried out for observing the mode's motion and computing the Rayleigh damping coefficient called mass coefficient $(\alpha)$ and stiffness coefficient $(\beta)$.

\subsection{Model in ANSYS}

Assuming the cables inclined at $45^{\circ}$, cables linked to the body $\left(\Delta_{X} \& \Delta_{Z}=0\right)$, high strength precast concrete (M50), 
Fig. 1 Cross-section of SFT

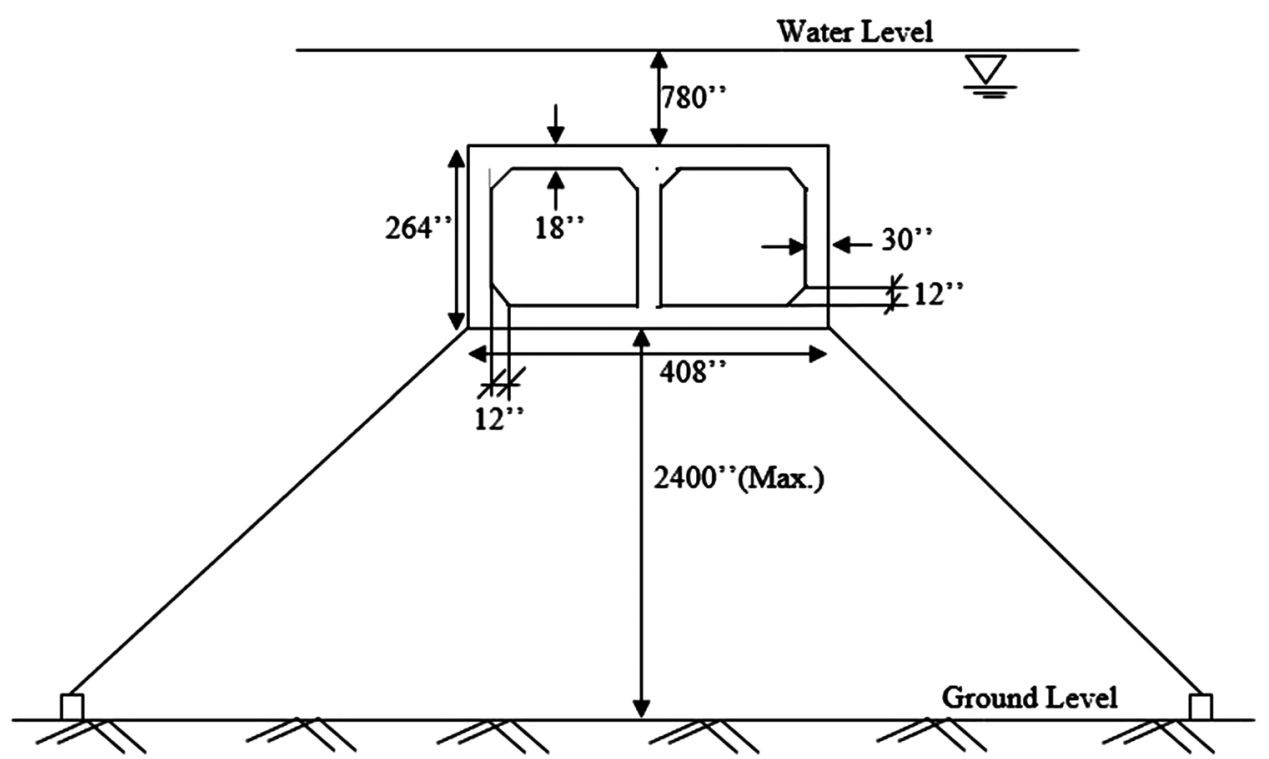

Table 1 Details of SFT Tube

\begin{tabular}{ll}
\hline Type & Magnitude \\
\hline Length & $300 \mathrm{ft}(91.44 \mathrm{~m})$ \\
Height & $22 \mathrm{ft}(6.7056 \mathrm{~m})$ \\
Width & $34 \mathrm{ft}(10.3632 \mathrm{~m})$ \\
Horizontal Slab $(\mathrm{t})$ & $1.5 \mathrm{ft}(0.4572 \mathrm{~m})$ \\
Vertical wall $(\mathrm{t})$ & $2.5 \mathrm{ft}(0.762 \mathrm{~m})$ \\
Carriageway & $12.25 \mathrm{ft}(3.7338 \mathrm{~m})$ \\
\hline
\end{tabular}

body to body fixed at internal rigid joints and constrained at both ends with connections, the SFT tube has been generalized as Fig. 2 in ANSYS. The whole SFT of some $300 \mathrm{ft}$ $(91.44 \mathrm{~m})$ is divided into six segments (M-1 \& M-2) with $50 \mathrm{ft}$ $(15.24 \mathrm{~m})$ of each, and it is set at $65 \mathrm{ft}(19.82 \mathrm{~m})$ from the water surface. Different supporting conditions for each module have been set that all DOFs are restrained at both ends $(\mathrm{M}-1)$ to ignore the large deformations which are assumed as the most realistic boundary condition constraining the rotation of SFT at the boundary. The module (M-2) is rigidly supported to the M-1 with the help of the rigid joint at both ends since the joints deserve the full authentication not to permit the water inside the tunnel, and the adjacent joints are designed for the connection of full strength. The stability of SFT is ensured by the adequate anchoring configuration

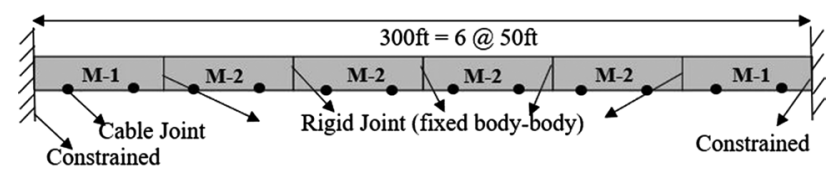

Fig. 2 Structural scheme of SFT (steel cables) fixed at lakebed and linked to the SFT with the help of spherical hinges in which displacement in $X$ and $Y$ directions is equal to zero $(0)$. Total thee pairs of inclined steel cables are configured at $45^{\circ}$ for the single module before the net buoyancy.

Rectangular SFT is such a structure whose structural geometry and the scheme are not too critical; nevertheless, the response of SFT to the dynamic actions or excitations can be complex due to the nonlinear behaviors of the anchorages. As a result, it is apt for performing FEA to have an inspection of the dynamic behaviors considering the novelty of typology and the importance of such structure owing to the peculiarities of structural condition and assessment of SFT against the hydrodynamic and environmental actions; the more development of analysis is needed to have efficient results. In this context, direct mesh generation is set since it will take the feasible shape of the irregular edges and vice versa, but the size of the meshing is put manually as 24 in $(0.6096 \mathrm{~m})$. During the generating mesh, ANSYS (ANSYS Workbench Version 15) selects the six elements like SOLID 186, TARGE 170, CONTA 174, SURF 154, MPC 184, CLOAD 201 (FOLLW 201) automatically from its element's library [23].

\subsection{Mathematical formulation of free vibration analysis}

Simple models are more useful for the evaluation of preliminary design in engineering practice since a designer can dimension in the first phase. The seismic and hydrodynamic analysis is more required for the SFT structure. Therefore, the simplified model allows the preliminary assessment of the structural dimensions. In this context, an equivalent elastic foundation for beam (BOEF) can be used for the initial model 
of SFT that presents the small dimensions as compared to crossing length and the SFT can be modeled as the beam. Since the SFT is modeled in several segments and supported by end joints, a segment can be assumed as a simply supported beam. The elastic supports represent the anchorage of the SFT. The respective SFT, BOES model and BOEF are shown in Fig. 3.

A single segment of SFT can be imagined like BOEF having elastic supports (stiffness, $K_{s}$ ) in both vertical and horizontal planes based on the mechanical behaviors and degrees of the anchorages. An equivalent Young's modulus can be also considered while the cable is used as anchorage. The model of a beam on elastic spring can be replaced with BOEF of stiffness $K_{s}$. So, the dynamic equilibrium of motion for free vibration leads to Eq. (1).

$\mathrm{El} w^{i v}(x, t)+m \ddot{w}(x, t)+c \dot{w}(x, t)+K_{\mathrm{s}} w(x, t)=0$

where El flexural rigidity or bending stiffness (included added mass), $w$ beam/tunnel deflection at the abscissa $x$.

Considering a solution for Eq. (1) in accordance with the Lagrange equation of Global Mode Method 5 conforming four conditions such as free linearly set, dimensionless, derivatives of degree in $V$, and admissible function (Fig. 4).

$W(x, t)=\Psi_{\mathrm{n}}(x) \Phi_{\mathrm{n}}(t)$

\section{Modal analysis}

The present study presents the mobile properties of the structure in the frequency domain. The overall stiffness and mass for finding out the different frequencies at which the structure can naturally resonate have been utilized. It is utilized to determine the eigenvalues corresponding to the mode shape, eigenfrequencies and modal mass participation of the structure. The equation of the dynamic equilibrium for establishing the general eigenvalue problem is as follows:

$M \ddot{w}+C \dot{w}+K w=P(t)$

where $M$ Modal mass of the SFT, C Damping of the SFT, $w$ Displacement, $P$ Time-varying load.

\subsection{Eigenvalues and eigenfrequencies}

The equation of dynamic equilibrium can be motivated considering the undamped free vibration $(C=0 \& P=0)$. So, we can have as follows

$M \ddot{w}+K w=0$

where $w=\varphi \sin (\omega t), \dot{w}=\omega \varphi \cos (\omega t), \ddot{w}=-\omega^{2} \varphi \sin (\omega t)$, $\varphi=$ Eigenvector, $\omega=$ Frequency in rad $/ \mathrm{s}$.

Compromising the harmonic vibrational principles, the characteristics equation is as follows:

$\left|K-\omega^{2} M\right|=0$

where $K$ stiffness and $M$ Modal mass.

The natural frequencies are most important relating to loading externally and overall response of the tunnel. The response of the global model might be high when the frequencies of the external loadings are in the range of the modal frequency. It is needed for the modes with large effective modal mass participation.
Fig. 3 Idealization of SFT as BOEF
(A) Submerged Floating Tunnel

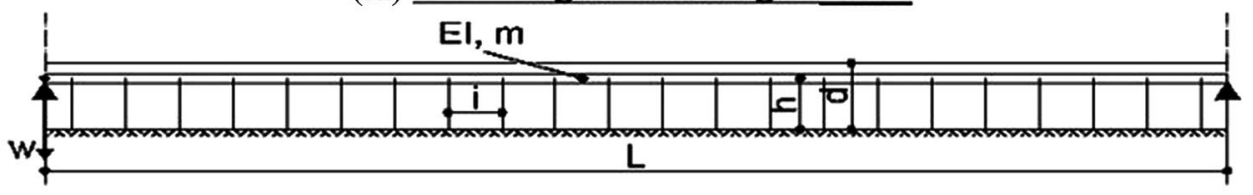

(B) Beam on Elastic Supports model

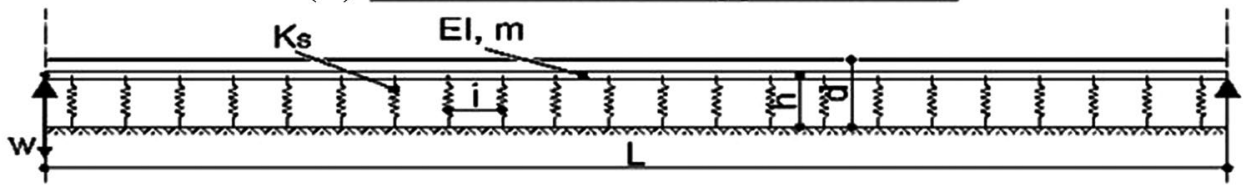

(C) Beam on Elastic Foundation model

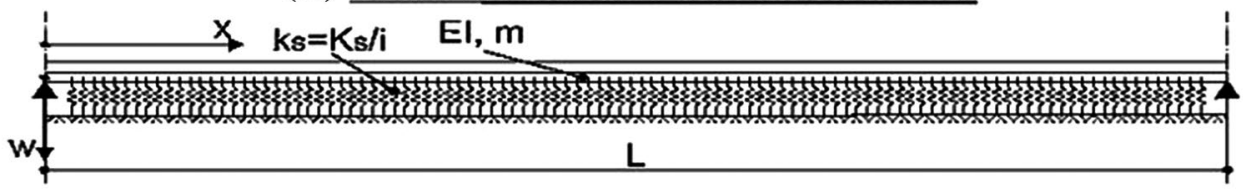



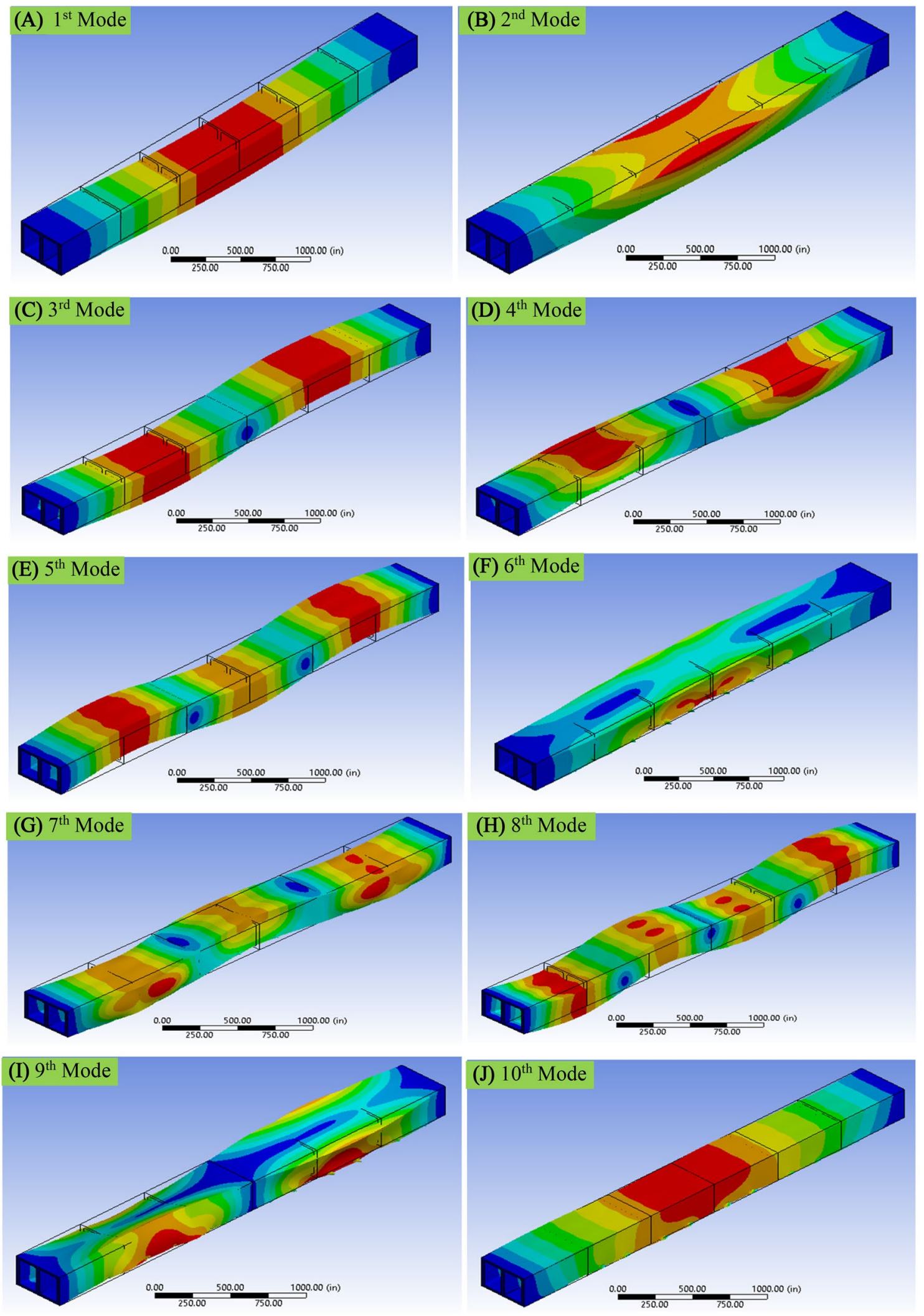

Fig. 4 Global mode shapes 


\subsection{Participated modal mass}

Modal mass participation is carried out for having significant modes to measure the Rayleigh damping coefficients. By Chowdhury and Dasgupta (2003), approximately $95 \%$ of the modal mass in all directions should need to carry the procedure of Rayleigh damping coefficients. But for $95 \%$ of modal mass participation, many modes are required which is a tedious fact. So as per Earthquake Resistant Design of Structures (Agarwal and Shrikhande), at least $90 \%$ of modal mass participation is required in all directions. Therefore, $90 \%$ of the modal is selected for the proceeding on the analysis and ANSYS solver provides $90 \%$ of modal mass participation in all directions for the first significant 150 modes. For ith mode,

$M_{i}=P_{i}^{2} \times m_{i}$

where $P_{i}=-\left(\varnothing_{i}^{\top} M_{r}\right) / m_{i}$ Modal Participation factor, $m_{i}$ Mass at $i$ th mode, $\varnothing_{i}$ Mode shape at ith mode.

\subsection{Rayleigh damping coefficient}

Rayleigh damping has come out of "Mass-Spring-DashpotSystem (Linear Theory)" where the mode shape can easily be idealized. Damping used in the dynamic equilibrium equation is expressed by the governance of the two coefficients called the coefficients of Rayleigh damping. The coefficients of Rayleigh damping for a large system can be computed from the following equation:

$C=\alpha M+\beta K$

where $\alpha=$ damping coefficient of mass and $\beta=$ damping coefficient of stiffness.

The behavior of mass coefficient can be drawn from the Table 2.

Performing the orthogonal transformation, the uncoupled damping ratio for $i$ th mode is as follows:

$2 \xi_{i} \omega_{i}=\alpha+\beta \omega_{i}^{2}$

$\xi_{i}=\frac{\alpha}{2 \omega_{i}}+\frac{\beta \omega_{i}}{2}$

Table 2 General values of mass coefficient [24]

\begin{tabular}{ll}
\hline General value & Effect \\
\hline$\alpha=0.05$ & Very little damping \\
$\alpha=2.5$ & Noticeable damping \\
$\alpha=5-10$ & Very noticeable damping \\
$\alpha>10$ & Pronounced damping
\end{tabular}

The modal damping ratio is sometimes divided into a nonlinear and a linear term since many structures are of higher frequency. Considering the realistic facts, the damping ratio and frequency are considered as linear. On this context, the damping ratio for ith mode is as follows:

$\xi_{i}=\frac{\xi_{m}-\xi_{1}}{\omega_{m}-\omega_{1}}\left(\omega_{i}-\omega_{1}\right)+\xi_{1} ; \quad 1<i<m$

$\xi_{i}=\frac{\xi_{m}-\xi_{1}}{\omega_{m}-\omega_{1}}\left(\omega_{i+1}-\omega_{m}\right)+\xi_{1} ; \quad m<i<2.5 m$

After getting the required mode shapes, the damping coefficient of mass and stiffness can be computed from the following equations

$\beta=\frac{2 \xi_{1} \omega_{1}-2 \xi_{m} \omega_{m}}{\omega_{1}^{2}-\omega_{m}^{2}}$

$\alpha=2 \xi_{1} \omega_{1}-\beta \omega_{1}^{2}$

Following the Chowdhury and Dasgupta (2003), 2.5 times of $\mathrm{m}$ modes are required for significant modes for Rayleigh damping. And the modes should accommodate approximately $95 \%$ of modal mass significance. So, a total of 375 eigenmodes are required for estimating the $a$ and $\beta$. Generally, a $5 \%$ damping ratio is considered for concrete structures, but a few experts suggest using $2-10 \%$ damping in marine structures. Therefore, considering the safety issues, here $2-10 \%$ damping to the critical damping is chosen to compute the coefficient.

\section{Result and discussion}

\subsection{Eigenvalues and eigenfrequencies}

From the ANSYS solver, the first 10 significant modes are tabulated with periods and direction of the mode's motion in the following Table $3 . \mathrm{H}, \mathrm{V}$ and $\mathrm{A}$ represent the horizontal, vertical and angular motion of the modes respectively. Table 3 shows that the frequencies (maximum $=114.069 \mathrm{~Hz}$ and minimum $=4.45883 \mathrm{~Hz}$ ) of the global SFT model increase with the alleviating of periods (maximum $=0.22472 \mathrm{~s}$ and minimum $=0.0087666 \mathrm{~s}$ ).

\subsection{Mode shape}

Mode shape is a pattern of vibration executed by a mechanical system at a specific frequency, and different frequency exerts different mode shapes. Here, the first 10 mode shapes are figured below corresponding to their 
Table 3 Eigenfrequencies and Modes' motion

\begin{tabular}{llllllll}
\hline Mode & Frequency $(\mathrm{Hz})$ & Period (S) & $\begin{array}{l}\text { Mode's } \\
\text { motion }\end{array}$ & Mode & Frequency (Hz) & Period (S) & Mode's motion \\
\hline 1 & 4.45883 & 0.22427 & $\mathrm{~V}$ & 6 & 22.5637 & 0.04432 & $\mathrm{~A}$ \\
2 & 9.86726 & 0.10135 & $\mathrm{~A}$ & 7 & 25.1849 & 0.03971 & $\mathrm{H} \& \mathrm{~V}$ \\
3 & 10.6906 & 0.09354 & $\mathrm{~V}$ & 8 & 27.8115 & 0.03596 & $\mathrm{~V}$ \\
4 & 18.1663 & 0.05505 & $\mathrm{~A}$ & 9 & 28.3941 & 0.03522 & $\mathrm{~A}$ \\
5 & 18.7228 & 0.05341 & $\mathrm{~V}$ & 10 & 30.5412 & 0.03274 & $\mathrm{H} \& \mathrm{~V}$ \\
\hline
\end{tabular}

Table 4 Total modal mass participation

\begin{tabular}{ll}
\hline Direction & $\begin{array}{l}\text { Participat- } \\
\text { ing mass } \\
(\%)\end{array}$ \\
\hline$X$ & 95.832 \\
$Y$ & 95.777 \\
$Z$ & 90.8307 \\
\hline
\end{tabular}

participation of mass occurs at 2 nd mode, 1 st mode and 10th mode in $X, Y$, and $Z$ directions, respectively. From the modal mass participation, it has been seen that SFT needs the first 14 modes in the $X$ direction, 13 modes in the $Y$ direction and 150 modes in the $Z$ direction for a minimum of $90 \%$ effective mass participation to the total mass.

\subsection{Rayleigh damping coefficient}

To evaluate the Rayleigh damping coefficient ( $a$ and $\beta$ ), 150 significant modes provide $90 \%$ modal mass participation and total significant 375 eigenmodes are calculated for the performing calculation. Considering 2-10\% damping to the critical, the following estimation is formed and the values of $\alpha$ and $\beta$ are given in Table 5. Confirming Tables 2 and 6, it can be said that the SFT is under noticeable damping. After computing the coefficient, damping ratios for each approximation are plotted together with linearized damping ratios.

\section{Conclusion}

SFT which has the characteristics of tunneling and marine engineering is of complexity in some disciplinary areas. It is too important to build the prophases of research for widening the aspects of crossing projects. After a critical analysis, it can be said:

- The SFT is under noticeable damping with a noticeable fundamental natural frequency.

- The computed mass coefficient $(a)$ is relatively high due to its heavy mass, and stiffness coefficient $(\beta)$ is also comparatively very low because of its slenderness.

So, it can be recommended to consider the circular or elliptical section depending on the past studies, since the rectangular section which has already high mass-coefficient is relatively prone to hydrodynamic actions because of galloping effects. terms of the feasible design.

Figure 6 shows the participated effective mass to the total mass in $X, Y$, and $Z$ directions. It shows that the most 


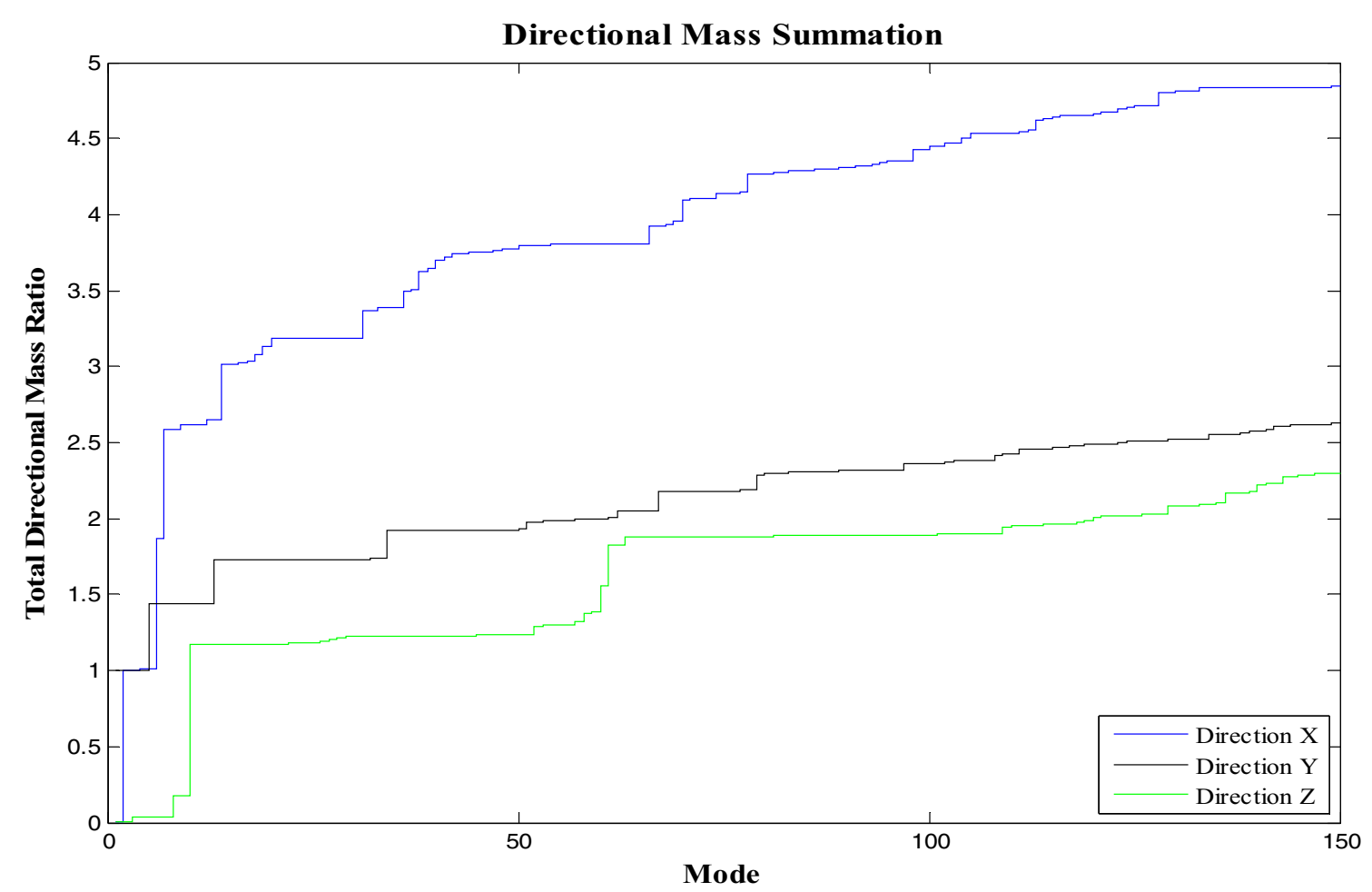

Fig. 5 Effective mass summation for global model

Fig. 6 Participation of effective modal mass

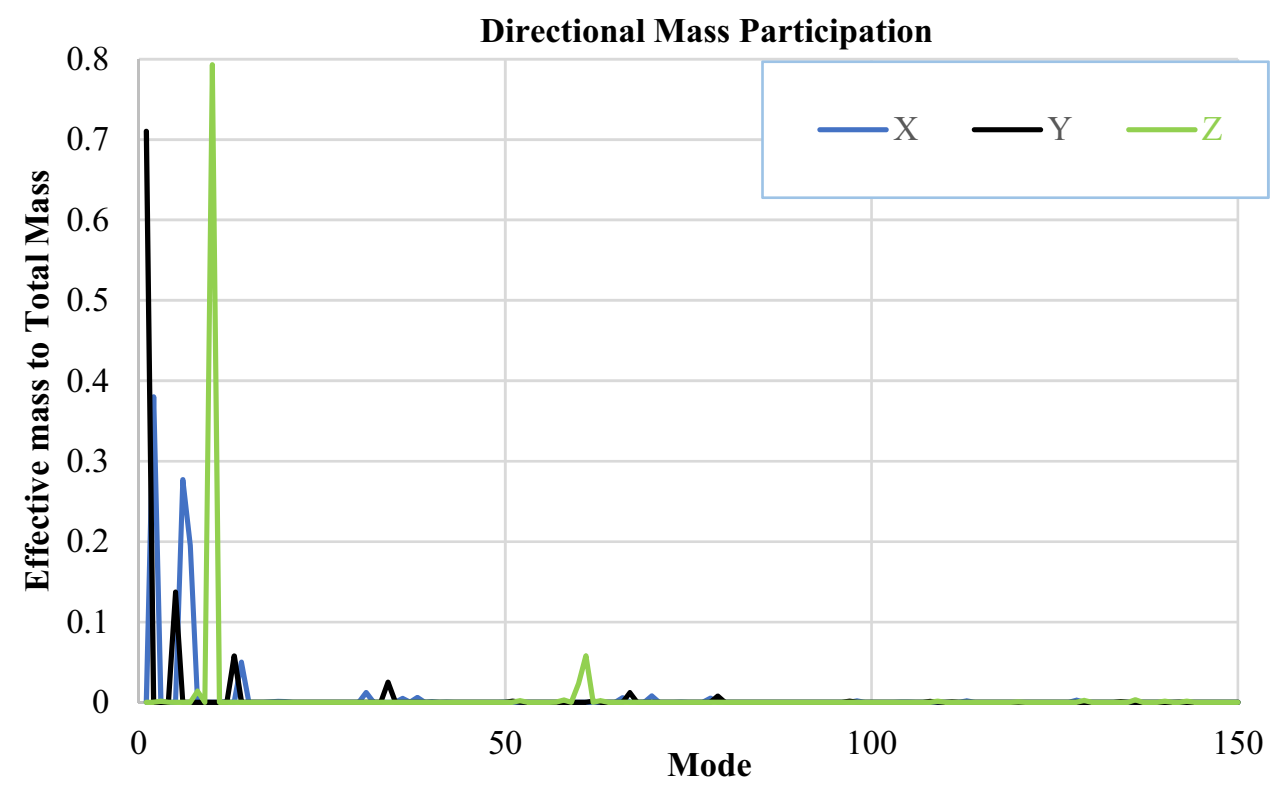


Table 5 Damping ratio for $m$ th and 2.5 th mode

\begin{tabular}{lccc}
\hline Mode & Frequency $(\mathrm{Hz})$ & Frequency $(\mathrm{rad} / \mathrm{s})$ & $\begin{array}{l}\text { Damping } \\
\text { ratio }(\zeta) \\
(\%)\end{array}$ \\
\hline 1st & 4.4588 & 28.016 & 2 \\
150th $(m \mathrm{th})$ & 114.069 & 716.717 & 10 \\
375th $(2.5 \mathrm{mth})$ & 292.3121 & 1836.6511 & 15.33 \\
\hline
\end{tabular}

Table $6 a$ and $\beta$ for different approximations

\begin{tabular}{llll}
\hline Coefficient & $m$ th mode & full mode $\left(2.5 \mathrm{~m}^{\text {th }}\right)$ & Average \\
\hline$A$ & 0.902994 & 0.989562 & 0.946278 \\
$B$ & 0.000277 & 0.000167 & 0.000222 \\
\hline
\end{tabular}

Acknowledgements Open access funding provided by University of Debrecen (DE). I overtly acknowledge that this work was performed for the M.Tech. thesis work at Sharda University, Greater Noida, India.

\section{Compliance with ethical standards}

Conflict of interest The authors declare that they do not have any conflicts of interest.

Open Access This article is licensed under a Creative Commons Attribution 4.0 International License, which permits use, sharing, adaptation, distribution and reproduction in any medium or format, as long as you give appropriate credit to the original author(s) and the source, provide a link to the Creative Commons licence, and indicate if changes were made. The images or other third party material in this article are included in the article's Creative Commons licence, unless indicated otherwise in a credit line to the material. If material is not included in the article's Creative Commons licence and your intended use is not permitted by statutory regulation or exceeds the permitted use, you will need to obtain permission directly from the copyright holder. To view a copy of this licence, visit http://creativecommons .org/licenses/by/4.0/.

\section{References}

1. Kang L, Ge F, Hong $Y$ (2016) A numerical study on responses of submerged floating structures undergoing vortex-induced vibration and seismic excitation. Proc Eng 166:91-98. https:// doi.org/10.1016/j.proeng.2016.11.569

2. Jakobsen $B$ (2010) Design of the submerged floating tunnel operating under various conditions. Proc Eng 4:71-79. https:// doi.org/10.1016/j.proeng.2010.08.009

3. Zhang K, Xiang Y, Du Y (2010) Research on tubular segment design of the submerged floating tunnel. Proc Eng 4:199-205. https://doi.org/10.1016/j.proeng.2010.08.023

4. Man-Sheng D, Xue-Fei T, Yuan Z, Fei T (2016) Vibration control of the submerged floating tunnel under the combined effect of internal wave and ocean current. Proc Eng 166:160-170. https ://doi.org/10.1016/j.proeng.2016.11.579

5. Yan H, Wu L, Yu J (2016) Mode analysis of the submerged floating tunnel tether. Proc Eng 166:136-142. https://doi.org/10.1016/j. proeng.2016.11.576

6. Muhammad N, Ullah Z, Dong-Ho C (2017) Performance evaluation of submerged floating tunnel subjected to hydrodynamic and seismic excitations. Appl Sci 7:1122. https://doi. org/10.3390/app7111122

7. Xiang Y, Yang Y (2016) Challenge in design and construction of submerged floating tunnel and state-of-art. Proc Eng 166:53-60. https://doi.org/10.1016/j.proeng.2016.11.562

8. Li K, Xinghong J (2016) Research on section form of submerged floating tunnels considering structural internal force optimization under fluid action. Proc Eng 166:288-295. https://doi. org/10.1016/j.proeng.2016.11.551

9. Lee JH, Seo S, Mun HS (2016) Seismic behaviors of a floating submerged tunnel with a rectangular cross-section. Proc Eng 127:32-47. https://doi.org/10.1016/j.oceaneng.2016.09.033

10. Lin W, Lin M, Yin H, Liu X (2019) Design of immersed tunnel and how we research submerged floating tunnel [Online First], IntechOpen. https://doi.org/10.5772/intechopen.88169

11. Chowdhury I, Dasgupta SP (2003) Computation of Rayleigh damping co-efficient for large systems. http://ejge.com/2003/ Ppr0318/Ppr0318.pdf

12. Mario P (2004) Structural dynamics: theory and computation, 2nd edn. CBS Publishers and Distributors, New Delhi

13. Damodarasamy SR, Kavitha S (2009) Basics of structural dynamics and aseismic design. Prentice-Hall of India, New Delhi

14. Chopra AK (2006) Dynamics of structures, 3rd edn. Wiley, London

15. Coutu A, Seeley C, Monette C, Nennemann B, Marmont H (2012) Damping measurements in flowing water. IOP Conf Ser Earth Environ Sci 15:062060. https://doi.org/10.1088/17551315/15/6/0620605

16. Bai Y, Bai Q (2005) Subsea pipelines and risers. Elsevier, New York. https://doi.org/10.1016/B978-0-08-044566-3.X5000-3

17. Agarwal $P$, Shrikhande $M(2006)$ Earthquake resistant design of structures. Prentice-Hall of India, New Delhi

18. AASHTO LRFD Bridge (2012) Standard specifications of highway bridges. American Association of State Highway and Transportation Officials, 17th Edition, Washington

19. Chakrabarti SK (2004) Handbook of offshore engineering. Offshore Structure Analysis, Inc., Plainfield, IL, USA

20. Chandrasekaran $S(2018)$ Dynamic analysis and design of offshore structures, vol 9, 2nd edn. Springer, Singapore

21. Dong RG (1978) Effective mass and damping of submerged structures, United States. https://doi.org/10.2172/7038325

22. Wang W, Dalton D, Hua X, Wang X, Chen Z, Song G (2017) Experimental study on vibration control of a submerged pipeline model by eddy current tuned mass damper. Appl Sci 7(10):987. https://doi.org/10.3390/app7100987

23. ANSYS Workbench version 15. ANSYS Inc (2013)

24. Autodesk Algor Simulation User's Guide Version 2010. Autodesk Inc (2010)

Publisher's Note Springer Nature remains neutral with regard to jurisdictional claims in published maps and institutional affiliations. 